chain action as suggested by Daneel, ${ }^{1}$ then anything which alters the degree of association of the water would influence the magnitude of this effect. In order, therefore, to estimate the degree of ionization of strong acids or alkalies in concentrated solutions, the best procedure would probably be to make use of the equation

$$
r=A / A_{\circ}^{\prime}
$$

in which $A$ is the equivalent conductance of the solution for which $\gamma$ is desired, and above which the vapor pressure of the water is $p . A^{\prime}$ is the equivalent conductance of the electrolyte at infinit dilution in a solution to which a suitable non-electrolyte has been added, so as to give it the same viscosity and the same vapor pressure, $p$, as the first solution. In the absence of any experimental data, however, equation (34) must be regarded merely as a suggestion.

\title{
Summary.
}

I. It is pointed out that in calculating the degree of ionization of an electrolyte by the conductivity method, the neglect of the viscosity effect may produce errors as high as 7 and 8 per cent., even at such low concentrations as o.I normal and for such simple electrolytes as uniunivalent salts.

2. The relation $A=k f^{m}$ (in which $A$ is the equivalent conductance of an ion, $f$ is the fluidity of the solution, $m$ is a constant not far from unity and dependent chiefly upon the nature of the ion, and $k$ is a proportionality constant) is proposed, provisionally as the most logical basis for formulating the viscosity correction in calculating the degree of ionization, $r$, in moderately concentrated solutions.

3. The above relation is shown to lead to the following expression for the degree of ionization: $\gamma=\Lambda / \Lambda_{0}\left(\eta / \eta_{0}\right)^{m}$. Examples illustrating the results obtained with this equation are given and methods for determining the "fluidity exponent," $m$, are discussed.

4. The relation $A=k f^{m}$ is shown to lead to the following expression for the true transference number $n_{\mathrm{A}}$ of the ion $A$ in any solution: $n_{\mathrm{A}}=$ $n_{O_{A}}\left(\eta / \eta_{0}\right)^{m_{A}-n} . \quad n_{O_{A}}$ is the transference number at infinit dilution in pure water, $\left(\eta / \eta_{0}\right)$ the relative viscosity of the solution, and $m_{\mathrm{A}}$ and $m$ are the "fluidity exponents" for the ion and for the salt, respectively. Values calculated from this equation are compared with those determined experimentally.

URBANA, ILL.

THE ACTION OF NITROGEN ON LITHIUM CARBIDE.

By S. A. Tucker ANd H. R. MOOdy.

Received July 1, 1911 .

Although particular attention has been given by many investigators

'Z. Elektrochem., II, 249 (Ig05). 
to the influence of nitrogen on calcium carbide, and the formation of calcium cyanamide, very little work appears to have been done on the action of nitrogen on the carbides in general.

Since lithium itself is known to form compounds with nitrogen it seemed desirable to begin a proposed series of investigations with lithium carbide. The investigation is taken up in the following manner:

I. Preparation of Lithium Carbide.

2. Analysis of Lithium Carbide.

3. Preparation of Nitrogen.

4. Absorption of Nitrogen by the Carbide. Method of Carrying on the Experiments, Temperature and Pressure.

5. Analysis of the Product, Total Nitrogen, Condition of Nitrogen in the Product.

6. Experimental Results: Influence of Temperature, Pressure, Time.

7. Conclusions.

\section{Preparation of Lithium Carbide.}

But little has been published on the preparation of this carbide. Guntz ${ }^{1}$ heated metallic lithium and carbon in the air, and in an atmosphere of nitrogen, he also heated the metal in the presence of the gases $\mathrm{CO}, \mathrm{CO}_{2}$, $\mathrm{C}_{2} \mathrm{H}_{2}, \mathrm{C}_{2} \mathrm{H}_{4}$ and $\mathrm{CH}_{4}$, and obtained some carbide but none of his experiments gave a pure carbide. His best results were obtained with the metal in an atmosphere of carbon dioxide. Moissan ${ }^{2}$ heated lithium carbonate and carbon in his electric furnace, the charge being placed in a carbon tube. The reaction was as follows:

$$
\mathrm{Li}_{2} \mathrm{CO}_{3}+{ }_{4} \mathrm{C}=\mathrm{Li}_{2} \mathrm{C}_{2}+{ }_{3} \mathrm{CO}
$$

Using 350 amperes at 50 volts seems to have given the best results, and he claims to have obtained nearly pure lithium carbide by this reaction. He noted that with 950 amperes decomposition of the carbide took place at the end of the fourth minute, and observed volatilization of the unchanged carbide, which condensed on the cooler portions of the tube.

The carbide so obtained is described as white with a crystallin fracture. The method followed by the authors for the preparation of this carbide was essentially that of Moissan. A mixture of lithium carbonate and carbon in molecular proportions was heated in three types of electric furnaces: granular-carbon, ${ }^{3}$ Borchers ${ }^{4}$ and vertical arc. ${ }^{5}$

The first, or granular carbon furnace, gave far the best results, and the preparation was carried out by heating the mixture in a graphite crucible, using from $25^{\circ}-65^{\circ}$ amperes at $15-30$ volts for from 15 to 17 minutes.

${ }^{1}$ Compt. rend., 123, $1273-5$ (1896).

Ibid., 127, 362 .

${ }^{3}$ S. A. Tucker, Trans. Am. Electrochem. Soc., 40, 307-15.

'Borchers-McMillan, "Electric Smelting and Refining," London, 1904, p. I03.

${ }^{5}$ S. A. Tucker, Vertical Arc Furnaces, Electrochem. Met. Ind., 4, (7) 263. 
On breaking the crucible, the carbide was easily detached from the bottom and sides, and was then analyzed for its content of carbide.

It was soon seen from these experiments that the production of pure lithium carbide was a matter of extreme difficulty, as it was clear that the temperatures of formation and dissociation were close together.

This property is indicated by Moissan's work as well, and it seems to us that to form any considerable mass of pure carbide in this way is practically impossible.

Moissan, as before stated, claims to have obtained nearly pure carbide, but if he did so, it must have been by selecting a small crystal or piece, which gave him the results in accordance with his analysis.

The product obtained by us was for the most part black, and the best results gave a carbide content of 53 per cent. which was obtained with the addition of 4 per cent. of manganese dioxide and a mixture of 60 parts of lithium carbonate and 48 parts of carbon.

The conditions given for the formation of the carbide in a resistance furnace of the granular-carbon type are of course difficult to duplicate on account of the change in the furnace itself. These changes include the variation of the carbon grains, the pressure to which they are subjected, and the number of times the coke has been previously heated in the electric furnace.

After making a number of runs, we were able to judge by the eye alone the right time to withdraw the crucible. When the charge begins to emit fumes of volatilizing metal it is necessary to stop immediately, otherwise the product will be largely contaminated with graphite. This point is also indicated by an apparent rise in temperature, which causes the gases to emit a dazzling white light. Moissan states that lithium carbide is volatil as such. From numerous experiments we have come to the conclusion that this is not the case but that it follows the usual property of the carbides in general of being decomposed by excessive heating into graphite and lithium. It is quite possible that in the dissociation, metallic lithium vapors on coming in contact with a relatively cooled carbon surface form carbide again. Or carbide may be formed by the Gunt $z$ reaction as follows:

$$
2 \mathrm{Li}+{ }_{2} \mathrm{CO}=\mathrm{Li}_{2} \mathrm{C}_{2}+\mathrm{O}_{2} .
$$

Either formation of lithium carbide would account for Moissan's belief that he had obtained volatilization of the carbide itself, since he made his preparation in a carbon tube.

The product obtained by the authors was neither uniform nor, as previously stated, pure carbide. Selected masses gave, on analysis, a carbide content of 53 per cent. and these masses were used on the subsequent work on nitrogen absorption. Taking the whole mass it would show a formation not much over 25 per cent. of the theoretical carbide 
yield that could be formed from the proportions of the charge taken.

It is thus seen that the preparation of lithium carbide is attended with difficulty and points to the small temperature interval between its formation and decomposition. Of the carbides studied in other lines of work we have found lithium carbide to possess this property in the most marked degree. The best conditions for preparation, as far as time of heating is concerned, are shown in the following table:

$\begin{array}{lcc}\text { Time. } & \text { Amps. } & \text { Volts. } \\ \text { II . } 45 & 210 & 18 \\ \text { II } .46 & 250 & 30 \\ \text { II } .49 & 320 & 30 \\ \text { II } .54 & 450 & 30 \\ \text { II.56 } & 650 & 30 \\ 12.00 & 680 & 30 \\ \text { I } 2.01 & 700 & 30\end{array}$

That is, the heating must be slow and the final high temperature must be of short duration.

With the conditions used by the authors the time of heating could never exceed I 7 minutes, the last few minutes being very critical.

Lithium carbide attacks almost any material in which it is heated-porcelain, alundum, graphite and even iron are corroded, the latter withstanding its action best.

\section{Analysis of Lithium Carbide.}

The value of the product was determined by decomposing with water a known weight of the carbide and noting the loss in weight due to the evolution of acetylene. The operation was carried on in a Rose and Geissler alkalimeter; precautions were taken to decompose the carbide slowly, and the gas as evolved was dried by passing through calcium chloride. Only sufficient water was added to thoroughly decompose the carbide, and towards the end the flask was heated to evolve acetylene which might have been dissolved in the water added.

\section{Preparation of Nitrogen.}

For the preparation of the nitrogen used in these experiments, molec1lar proportions of sodium nitrite and ammonium chloride were heated in solution according to the reaction:

$$
\mathrm{NaNO}_{2}+\mathrm{NH}_{4} \mathrm{Cl}=\mathrm{N}_{2}+\mathrm{NaCl}+2 \mathrm{H}_{2} \mathrm{O}
$$

This reaction is best carried out by delivering the nitrite solution from a stop-cock funnel to the solution of ammonium chloride contained in a round bottom Jena flask.

As the reaction is very active the gas is evolved rapidly without additional heating after the reacting temperature is reached. The nitrogen was washed, and then stored in gas holders until required for use.

On analysis the gas was found to contain some oxygen-generally 
from 1 to 2 per cent. As the presence of oxygen is known to be detrimental in the formation of calcium cyanamide from nitrogen and calcium carbide, the gas before using was purified of its admixed oxygen by passing it through a heated tube containing copper gauze. This gave a gas containing less than 0.1 per cent. oxygen by volume and was therefore passed directly into the absorption tube.

\section{Absorption of Nitrogen.}

As the experimental work involved exposing the heated carbide to the influence of nitrogen at varying pressure and temperature, the arrangement shown in Fig. I was adopted.

The first experiments were carried out at atmospheric pressure. Connection was made with the tube of the combustion furnace $C$, containing copper gauze, and the Calorite electric furnace ${ }^{1} G$, by means of rubber tubing. The electric furnace $G$ was heated to the required temperature and nitrogen passed through the system to displace air.

The carbide in fine powder contained in a porcelain boat holding about I gram was then placed in the furnace $G$, at $H$, temperature being read by the thermo-couple at the galvanometer I. Nitrogen was passed slowly through the tube during the time decided upon for the absorption and allowed to escape through a small opening at the end of the tube.

The current was then turned off the electric furnace and the tube was closed with a rubber stopper. The carbide was thus exposed to an atmosphere of nitrogen while cooling.

For use with nitrogen under pressure, the systems $D, E$, and $F$ were connected, consisting of a force pump $D$, which took nitrogen from the tube in the combustion furnace $C$. An automobil tire pump $\mathrm{I}^{3} /{ }_{4}^{\prime \prime}$ diameter was used; this was altered by placing two leathers on the plunger and providing two check valves with brass seats and rubber tips at the bottom.

The gage $E$ was an ordinary steam gage, reading

${ }^{1} \mathrm{~S}$. A. Tucker, "Electric Furnaces with Calorite Resisters for Laboratory Use", read at May, Igri, Meeting, N. Y. Sec., Am. Chem. Soc. 
to 200 pounds. A needle valve was placed below the gage so that it could be cut out. $F$ is another needle valve making connection with a Geryk oil pump to exhaust the air from the system before admitting nitrogen. The carbide contained in a small sheet-iron boat (as iron was found to be least attacked by the carbide) was placed in a special retort, Fig. 2, and connections were made on the pressure side of the system with good quality pressure tubing. Automobil pressure tubing of reinforced rubber is best for this use, as ordinary rubber pressure tubing will blow out at about 40 pounds.

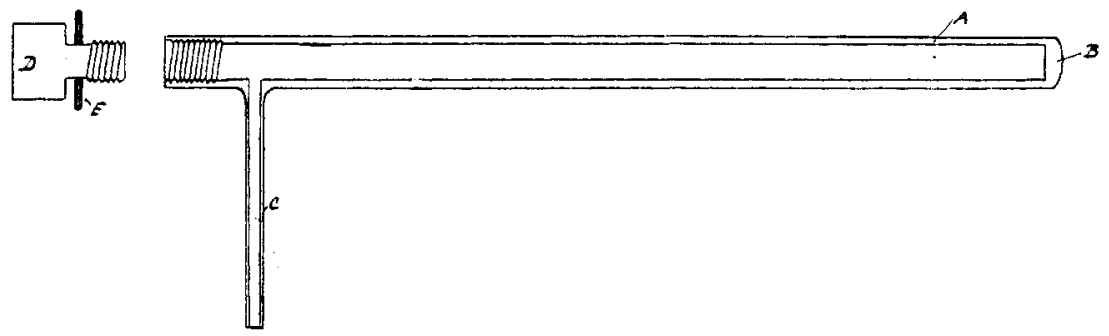

Fig. 2.

The retort shown in Fig. 2 was of cold-rolled steel tubing, $20 \mathrm{~cm}$. long, $18 \mathrm{~mm}$. inside diameter and $25 \mathrm{~mm}$. outside diameter. The end was autogenousiy welded in the oxyacetylene flame by inserting a steel plug and welding it gas-tight. The other end had a screw thread cut internally and a plug $D$ provided, the joint being made gas-tight by means of a standard asbestos copper gasket, $E . \quad C$ is an iron tube for admission of the nitrogen and is brazed into the tube $A$ with copper by the use of the oxyacetylene flame.

The iron boat containing the carbide was pushed to the end of the tube; pressure tubing was connected to $C$, and the system exhausted of air. The retort was then placed in the electric furnace $G$, the temperature adjusted to the required point, $F$ was closed, and a few strokes of the pump $D$ brought the pressure to 40 pounds. The valve below the gage $E$ was now opened and the pressure could be maintained by drawing in nitrogen on the suction stroke of the pump.

\section{Analysis of the Product.}

After treatment with nitrogen, the product was usually caked and brown, particularly on the surface. It was ground and well mixed and the total nitrogen determined by the Kjeldahl method.

As it was desired, if possible, to determin what compounds of nitrogen existed in the product, a method of analysis adopted by N. Caro ${ }^{1}$ and others was used, as follows: I gram of the sample was dissolved in 100 cc. of water, made strongly ammoniacal and excess of ammoniacal silver acetate added. The precipitate was filtered, washed free of ammonia

${ }^{2}$ N. Caro, B. Schück and R. Jacoby, $Z$. angew. Chem., 23, 2405 (1910). 
and the nitrogen determined by the Kjeldahl method. This gives the nitrogen as cyanamide.

For the determination of the dicyanamide, the filtrate was made alkaline with potassium hydroxide, boiled to evolve ammonia and then the nitrogen content of the precipitate, consisting of silver dicyanamide and oxide, determined by the Kjeldahl method.

For nitrogen as cyanide, the method of Feld ${ }^{1}$ was used, and consisted in evolving the nitrogen as hydrocyanic acid by distillation of the sample in the presence of lead nitrate solution. Sample No. 40, which had a nitrogen content of 3.18 per cent., gave the following results:

Per cent.

Nitrogen as cyanamide............. 63

Nitrogen as dicyanamide.............27

Nitrogen as cyanide................ 18

2.08

Sample No. $7 \mathrm{I}=13.5$ per cent. total nitrogen.

Nitrogen as cyanamide........... 5.2

Nitrogen as dicyanamide........... $3 \cdot 4$

$$
8.6
$$

In the latter sample the cyanide was not determined, but it would appear from these results that the product obtained by the action of nitrogen on lithium carbide differs considerably from the corresponding calcium product, or "nitrolime."

Caro gives analyses of "nitrolime" from the Spandau factory which show that nearly all the nitrogen is fixed as cyanamide, with small amounts of dicyanamide and traces of cyanide.

The remaining nitrogen in the authors' product is probably lithium nitride, as this compound is readily produced by the action of nitrogen on metallic lithium and it seems very likely that some metallic lithium would be formed in the preparation of the carbide as carried out in the electric furnace.

\section{Experimental Results.}

The results obtained are shown in the following tables:

Table I.-INFLUENCE OF TEMPERATURE.

$\begin{array}{cccc}\text { Run No. } & \begin{array}{c}\text { Temperature. } \\ \text { oC. }\end{array} & \begin{array}{c}\text { Per cent. of } \\ \text { nitrogen fixed. }\end{array} & \text { Time } \\ \text { Hour. } \\ 32 & 420 & 0.535 & \text { I } \\ 32 & 565 & 2.25 & \text { I } \\ 34 & 715 & 3.16 & \text { I } \\ 35 & 795 & 3.20 & \text { I } \\ 36 & 850 & 3.36 & \text { I } \\ 39 & 925 & 4.22 & \text { I } \\ 4 \text { I } & 1025 & 2.64 & \text { I }\end{array}$

'W. Feld, J. Gasbel., 46, [29] 561, [30] 603, [31] 629, [32] 642, [33] 660. 
THE HYDROLYSIS OF IODINE AND OF BROMINE.

TABLE II.-INFLUENCE OF TIME.

$\begin{array}{cccc}\text { Run No. } & \text { Time. } & \begin{array}{c}\text { Per cent. of } \\ \text { nitrogen fixed. }\end{array} & \begin{array}{c}\text { Temperature } \\ \text { Hour. }\end{array} \\ 47 & 1 / 2 & 2.92 & 925 \\ 39 & 1 & 4.22 & 925 \\ 42 \mathrm{~A} & 2 & 4.05 & 925 \\ 42 \mathrm{~B} & 3 & 2.53 & 925 \\ 42 \mathrm{C} & 4 & 0.66 & 925\end{array}$

Table III.-Influence of Pressure.

$\begin{array}{cccc}\text { Run No. } & \begin{array}{c}\text { Lbs. sq. inch } \\ \text { pressure. }\end{array} & \begin{array}{c}\text { Per cent. of } \\ \text { nitrogen fixed. }\end{array} & \begin{array}{c}\text { Time } \\ \text { Hour. }\end{array} \\ 43 & 35 & 10.04 & \text { I } \\ 59 & 50 & 16.20 & \text { I } \\ 7 \mathrm{I} & 80 & 13.5 & \text { I }\end{array}$

\section{Conclusions.}

The tables show, first, that more nitrogen is absorbed at a temperature of about $925^{\circ}$ than at either higher or lower temperatures; second, that the maximum absorption is reached in one hour and that decreased values are obtained with either longer or shorter periods of heating; and, third, that about $5^{\circ}$ pounds per square inch of nitrogen pressure gives the most efficient reaction.

The proportion of nitrogen fixed in the lithium compound does not differ greatly from that obtained commercially with "nitrolime," but the time necessary to so fix it is much less. The nature of the nitrogen compounds formed appears to differ considerably when lithium carbide is used from the compounds obtained when the nitrogen is absorbed in calcium carbide.

So far as the actual quantity of nitrogen so fixed is concerned, much better results might be anticipated with a purer carbide of lithium.

EIEctro-Chemical laboratory,

Colvmbia University,

NEW YORK CITY.

\section{THE HYDROLYSIS OF IODINE AND OF BROMINE. A CORREC- TION.}

BY WILLIAM C. BRAY AND E. I. CONNOLLY,

Received July 22, I9II.

The values of the hydrolysis constants $\left(\mathrm{H}^{+}\right)\left(\mathrm{I}^{-}\right)(\mathrm{HIO}) /\left(\mathrm{I}_{2}\right)=0.6 \times$ $\mathrm{IO}^{-12}$ and $\left(\mathrm{H}^{+}\right)\left(\mathrm{Br}^{-}\right)(\mathrm{HBrO}) /\left(\mathrm{Br}_{2}\right)=2.4 \times 1 \mathrm{I}^{-8}$, given in a recent article, ${ }^{1}$ were calculated from the results of conductance measurements of saturated aqueous solutions of the halogens on the assumptions that $\left(\mathrm{H}^{+}\right)=\left(\mathrm{I}^{-}\right)=(\mathrm{HIO})\left[=4.0 \times \mathrm{IO}^{-9}\right]$ and $\left(\mathrm{H}^{+}\right)=\left(\mathrm{Br}^{-}\right)=\mathrm{HBrO}[=0.00 \mathrm{I} 7]$. Dr. Anton Skrabal, of the Technische Hochschule, Vienna, has kindly

1 Thrs Journal, 32, 932 (1910). 